
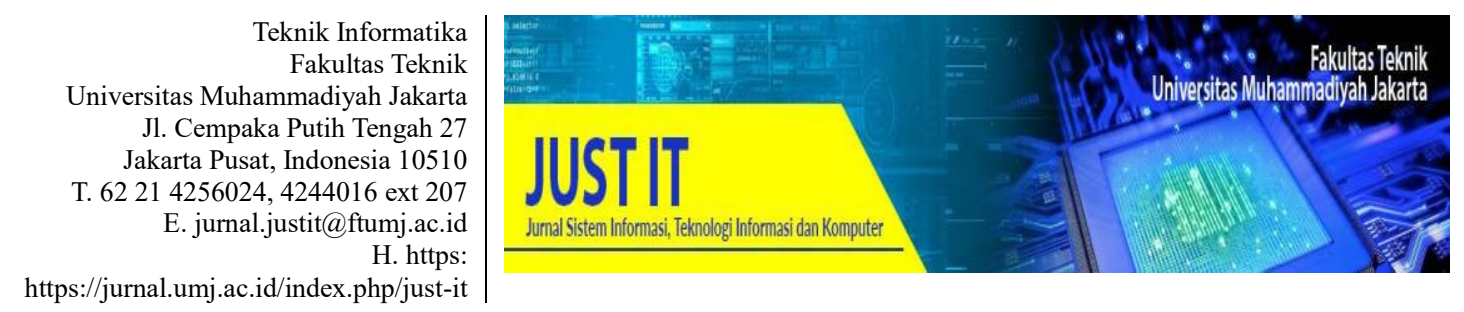

\title{
SISTEM INFORMASI ANTAR WARGA "SI-ANWAR" SEBAGAI SOLUSI Bermasyarakat di PERUMAHAN TIGARAKSA BERBASIS WEB
}

\author{
Ardhi Abdurrahman Ghozi ${ }^{1}$, Muhammad Taufik Hidayat ${ }^{2}$, dan Khoiru Rohman ${ }^{3}$ \\ Jurusan Sistem Informasi, Fakultas Ilmu Komputer, Universitas Mercu Buana
}

Ghoziardhi11@gmail.com¹,wysnured32@gmail.com²,khoirvandawa@gmail.com³

\begin{abstract}
Abstrak
Informasi sangat penting dalam mendukung kehidupan bermasyarakat, khususnya di perumahan. Masyarakat sangat membutuhkan akses informasi yang cepat dan efisien, Dengan berkembangnya teknologi belakangan ini dirasa sangat perlu dalam melibatkan teknologi dalam kehidupan bermasyarakat di perumahan. Masalah yang ada pada perumahan ini adalah kurang transparannya laporan keuangan dan adanya warga yang mengeluh karena tidak mendapatkan informasi yang jelas oleh karena itu warga menginginkan kemudahan dan kejelasan dalam mendapatkan informasi serta pelaporan yang lebih mudah tersampaikan kepada ketua RT. Mengingat warga dan ketua RT memiliki kesibukan masing-masing sehingga mengalami kesulitan untuk saling bertemu. Setelah melakukan studi lapangan penulis merasa perlu untuk membuat Sistem Informasi guna menyelesaikan permasalahan tersebut. Penulis merasa aplikasi tersebut diperlukan untuk mempermudah warga sekitar untuk mendapatkan informasi secara digital dan real time. Penulis menganalisa dan merancang aplikasi tersebut dengan menggunakan metode waterfall dan dengan tahapan analisis kebutuhan sistem, desain dan perancangan menggunakan UML, Pengkodean menggunakan PHP dan pengelolaan database menggunakan MySQL. Dengan memanfaatkan kemajuan teknologi memberikan pelayanan publik yang transaparan dan akuntabel dalam memenuhi kebutuhan kemudahan dalam bermasyarakat.
\end{abstract}

Kata Kunci: Informasi, perumahan, digital, real time

\begin{abstract}
Information is very important to support social life, especially in a residential area. People is very need to accsess information quickly and efficiently, with the development of technology it feels very necessary to involve technology in social life in residential area. Every residential area have a problem, the problem is people in that area shares the information manually using the speaker from the mosque. After doing the field research author feels very necessary to make an application to finish the problem. The application name is "Sistem Informasi Antar Warga "SIANWAR" ". Author feels that application can make citizen easier to get a digital information and realtime. The author analyze and designs application built with the waterfall metho, with stages of system requirements analysis, design using UML. The coding system uses PHP and database managers using MySQL .
\end{abstract}

Keywords: Information, Residential area, digital, real time 


\section{PENDAHULUAN}

Perumahan Tigaraksa merupakan sebuah komplek pemukiman yang berada di Jl. Kadu Agung, Tigaraksa, Tangerang, Banten. Informasi sangat penting dalam mendukung kehidupan bermasyarakat, khususnya di perumahan. Masyarakat sangat membutuhkan akses informasi yang cepat dan efisien, Dengan berkembangnya teknologi belakangan ini dirasa sangat perlu dalam melibatkan teknologi dalam kehidupan bermasyarakat di perumahan.

Dengan perkembangan teknologi dan ilmu pengetahuan yang sangat pesat saat belakangan ini, masyarakat akan semakin memerlukan teknologi (Mukhtar, 2017). Salah satu teknologi yang berkembang saat ini adalah komputer, hal ini merupakan bentuk kemajuan teknologi yang memiliki peranan penting dalam mengolah data menjadi informasi yang akurat dan bermanfaat (Suryana \& Rizki, 2014). Dengan memanfaatkan teknologi saat ini, perlu adanya sebuah system baru yang harus diterapkan guna mendukung pelayanan terhadap masyarakat (STMIK Pringsewu \& Aprilia, 2017). Untuk meningkatkan pelayanan kepada masyarakat dibutuhkan sistem informasi berbasis website yang dapat memberikan kemudahan dan kejelasan dalam mendapatkan informasi serta pelaporan yang lebih mudah tersampaikan kepada ketua RT (Melinda, Borman, \& Susanto, 2017),(Sri \& Wijaya, 2016), (Rico Renaldi Polii, Rindengan, \& Karouw, 2017), (Pratama, Tania, \& Firdaus, 2018), (Raharjo, Nurhayati, \& Martono, 2017). Pelaporan terhadap kerusakan fasilitas - fasilitas umum merupakan salah satu hal penting Karena Kenyamanan atau keamanan merupakan hal penting yang harus terpenuhi (Nurnawati \& Hibatullah, 2018). Tindak pencurian di kawasan perumahan menjadi salah satu bentuk kejahatan yang menjadi fenomena kompleks saat ini oleh karena itu diperlukan adanya media pelaporan yang cepat agar mudah dalam menangani laporan yang ada (ASNAWI, 2018).

Masalah yang ada pada perumahan ini adalah kurang transparannya laporan keuangan dan ada warga yang mengeluh karena tidak mendapatkan informasi yang jelas oleh karena itu warga menginginkan kemudahan dan kejelasan dalam mendapatkan informasi serta pelaporan yang lebih mudah tersampaikan kepada ketua RT. Mengingat warga dan ketua RT memiliki kesibukan masing-masing sehingga mengalami kesulitan untuk saling bertemu.

Metode yang kami gunakan untuk mengembangkan sistem ini adalah metode waterfall. Menurut pressman (2015) Metode Waterfall terdiri dari 5 tahap yaitu communication, planning, modeling, construction, dan yang terakhir adalah deployment

Dengan memanfaatkan kemajuan teknologi ini diharapkan dapat memberikan kemudahan dalam bermasyarakat, adanya transparansi dalam laporan keuangan, informasi cepat didapat dan pelaporan warga cepat ditanggapi dengan baik, keadaan lingkungan juga kondusif, bersih, aman dan nyaman. Sehingga terciptanya pelayanan publik yang transaparan dan akuntabel dalam memenuhi kebutuhan kemudahan dalam bermasyarakat.

Pendekatan yang dilakukan pada penelitian ini dapat dikelompokan menjadi beberapa tahapan, antara lain :

1. Pengumpulan Data .

Pada tahap ini penulis melakukan observasi, wawancara dan riset pustaka guna mengumpulkan informasi terkait penelitian yang penulis lakukan

\section{Pengembangan Sistem}

Setelah penulis mengumpulkan data dan informasi, penulis memulai pengembangan sistem dalam hal ini penulis menggunakan metdoe waterfall

\section{METODE}

Pengembangan sistem yang dilakukan di penelitian ini menggunakan metodologi waterfall dan menggunakan bantuan UML untuk mengetahui fungsional sistem.

Terdapat beberapa tahapan yang berurut yaitu communication, planning, modeling, construction, dan yang terakhir adalah deployment (Roger S. Pressman, 2012) 


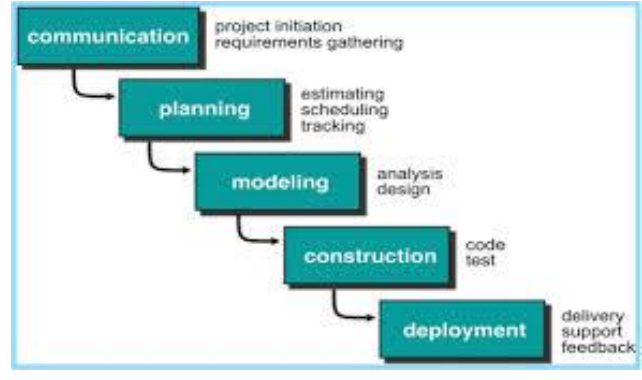

Gambar 1. Siklus Waterfall.

\section{Comunication}

Tahap ini dilakukan komunikasi kepada calon pengguna sistem untuk mengumpulkan informasi mengenai sistem yang diinginkan oleh pengguna dan batasan sistem. Informasi ini bisa di dapatkan melalui wawancara, diskusi, atau survey langsung.

\section{Planning}

Pada tahapan ini kegiatan yang dilakukan adalah membuat daftar estimasi waktu pengembangan sistem dan penjadwalan kerja yang akan dilakukan, resiko yang akan terjadi, serta sumber daya yang di butuhkan dalam mendukung pengembangan sistem contohnya seperti biaya yang dibutuhkan, jumlah orang yang terlibat dalam pengembangan sistem.

\section{Modeling}

Tahap ini yang dilakukan adalah peracangan serta pemodelan arsitektur sistem antara lain perancangan struktur data, arsitektur sistem, tampilan antar muka/ Interface dan algoritma program, tujuan dilakukannya kegiatan tersebut adalah untuk memahami gambaran besar dari apa yang dilakukan.

\section{Construction}

Tahapan ini merupakan proses penerjemahan desain menjadi kode program atau bahasa yang dapat dimengerti oleh mesin di tahapan ini juga dilakukan proses testing atau ujicoba setelah proses pengkodean selesai , tujuannya adalah untuk mengetahui kesalahan yang mungkin terjadi untuk nantinya di perbaiki

\section{Deployment}

Tahapan ini dilakukannya proses implementasi sistem kepada pengguna, pemeliharaan sistem, serta perbaikan sistem apabila terjadi kerusakan dan yang terakhir adalah evaluasi serta pengembangan sistem berdasarkan tanggapan yang diberikan oleh pengguna agar sistem dapat berjalan dan berkembang dengan baik sesuai dengan fungsinya.

\section{HASIL DAN PEMBAHASAN}

Berikut merupakan hasil analisis dan perancangan yang dilakukan terhadap masalah yang ditemui

\section{Analisa Sistem Berjalan}

Berikut sistem analisa berjalan pada Perumahan Tigaraksa :

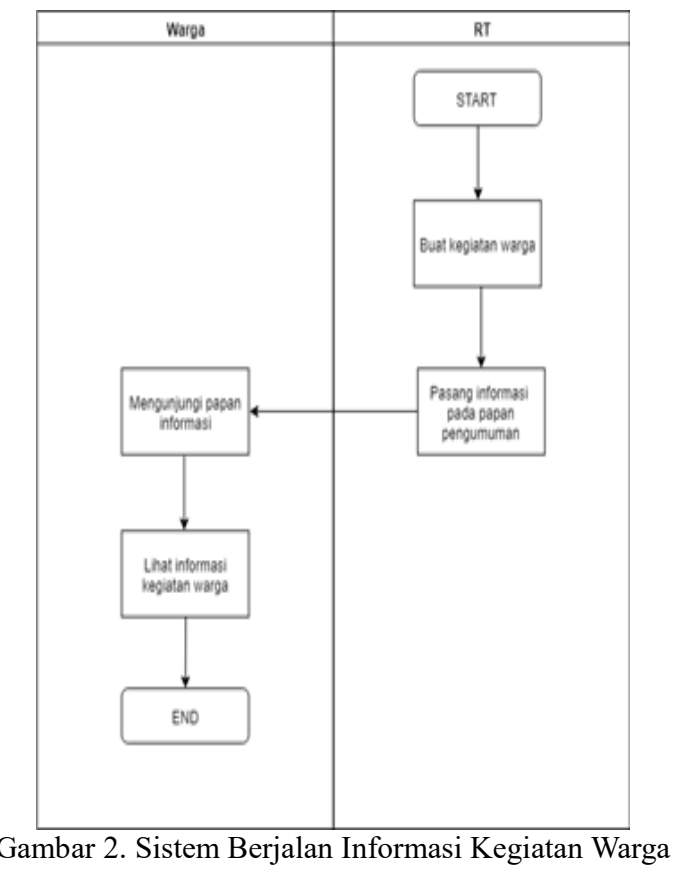

1. Proses pembuatan kegiatan warga secara manual oleh ketua RT/RW

2. Proses pemasangan informasi yang telah di buat pada papan pengumuman

3. Proses mengunjungi papan informasi untuk melihat yang telah ditempel oleh ketua RT/RW

4. Warga melihat informasi kegiatan warga pada papan pengumuman 


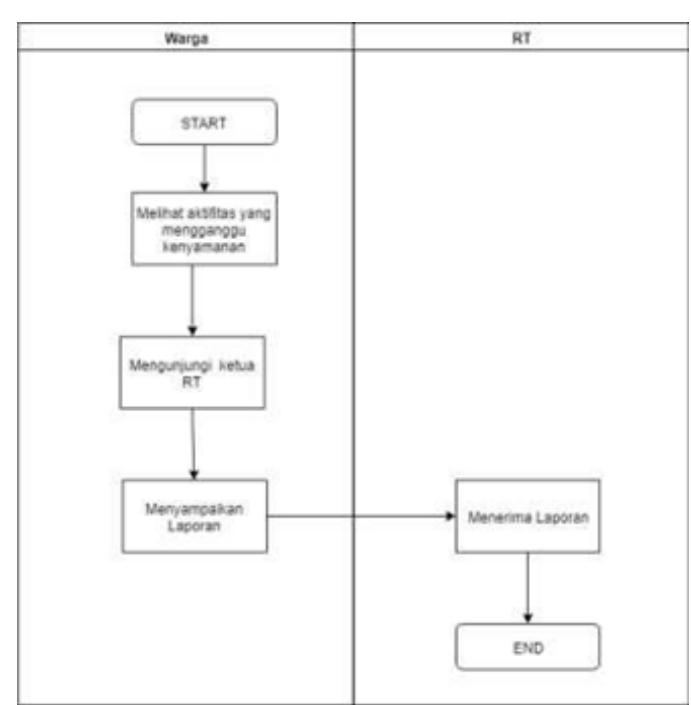

Gambar 3. Sistem Berjalan Laporan Warga

1. Warga melihat aktifitas yang mengganggu kenyamanan warga

2. 2. Warga mengunjungi ketua RT untuk melaporkan aktifitasyang mengganggu kenyamanan warga

3. Warga menyampaikan laporan atas aktifitas yang menggangu kenyamanan warga

4. Ketua RT menerima laporan dari warga

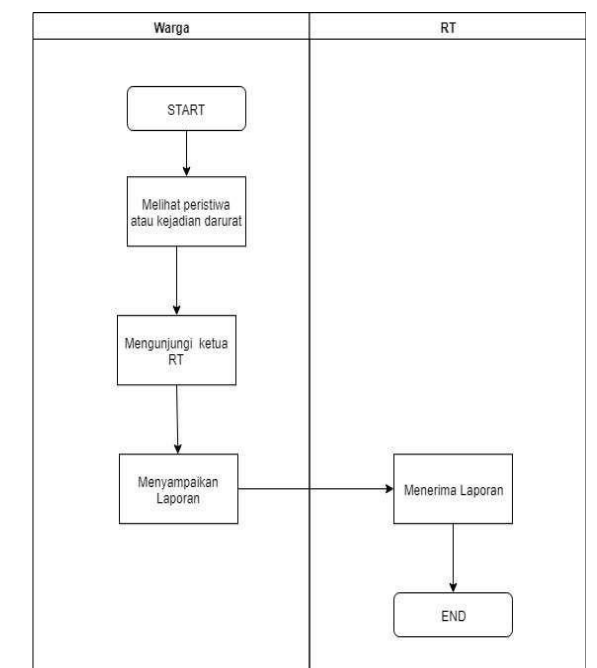

Gambar 4. Sistem Berjalan Laporan darurat warga

1. Warga melihat peristiwa atau kejadian darurat

2. Waga mengnjungi tetangga terdekat untuk melaporkan peristiwa atau kejadian tersebut

3. Warga menyampaikan laporan atas peristiwa atau kejadian darurat tersebut kepada tetangga terdekat
4. Warga lain menerima laporan dari warga yang melihat peristiwa atau kejadian darurat.

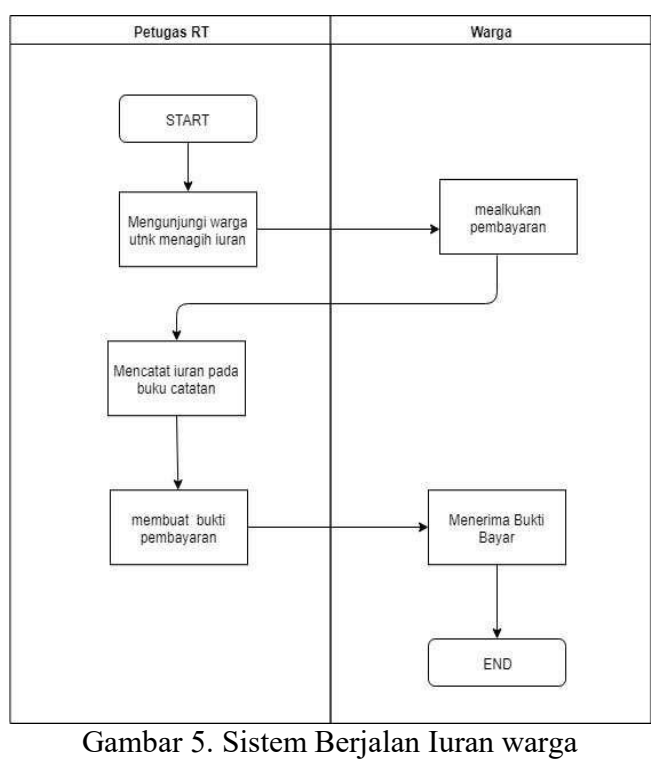

1. Petugas RT mengunjungi warga untuk menagih iuran bulanan

2. Warga melakukan pembayaran melalui petugas RT

3. Petugas RT melakukan pencatatan iuran bulanan pada buku catatan

4. Petugas RTmembuat bukti pembayaran iuran bulanan warga

5. Warga menerima bukti pembayaran yang menandakan bahwa warga tersebut sudah melakukan pembayaran iuran bulanan

\section{Analisa masalah dan kebutuhan}

Berdasarkan analisa sistem berjalan, maka dilakukan analisa sistem yang memberikan solusi untuk perbaikan performance maksimal dalam pembuatan sistem dan dimplementasikan dimasa yang akan datang. Berikut analisa masalah menggunakan metode PIECES :

1. Performance

Penyampaian informasi tentang kegiatan warga, pelaporan aktifitas atau fasilitas yang menggangu kenyamanan warga, pelaporan peristiwa atau kejadian darurat dan pencatatan iuran warga saat ini dilakukan secara manual. Ketua RT dan petugas RT harus melakukan kunjungan langsung menemui warga 
dalam menyampaikan informasi tentang kegiatan warga dan dalam pencatatan iuran bulanan warga dan warga harus melaporkan suatu laporan warga kepada RT dengan mengunjungi Ketua RT.

2. Information

Penyebaran informasi terkait kegiatan warga dirasa masih tidak merata dikarenakan hanya ditempel di papan pengumuman RT sehingga warga perumahan yang jarang bersosialisasi atau jarang mengunjungi papan pengumuman RT akan sulit mendapatkan informasi tersebut.

3. Economy

Penyampaian informasi tentang kegiatan warga secara manual untuk mencetak pengumuman kegiatan warga dan menempelnya di papan pengumuman membutuhkan biaya untuk proses tersebut.

4. Control

Pengawasan terkait masalah pada fasilitas dan kondisi yang dapat mengganggu warga di lingkungan perumahan masih belum terawasi dengan baik.hal tersebut sering kali tidak mendapatkan respon dari RT dan RW setempat dikarenakan kurangnya informasi.

5. Efficency

Penyampaian informasi terkait agenda warga, dan laporan warga saat ini masih mengggunakan cara manual dengan cara, masing masing warga melaporkan dan menginformasikan ke warga lain atau ketua RT/RW, hal tersebut dirasa kurang efisien dikarenakan informasi yang tersebar kurang merata dan memerlukan waktu dan tenaga untuk penyampaian tersebut.

6. Service

Warga tidak dapat mengetahui infromasi terkait warga di dalam satu perumahan secara menyeluruh, serta sulitnya warga dalam menyampaikan laporan kepad $\mathrm{RT} / \mathrm{RW}$.

\section{Use Case Diagram}

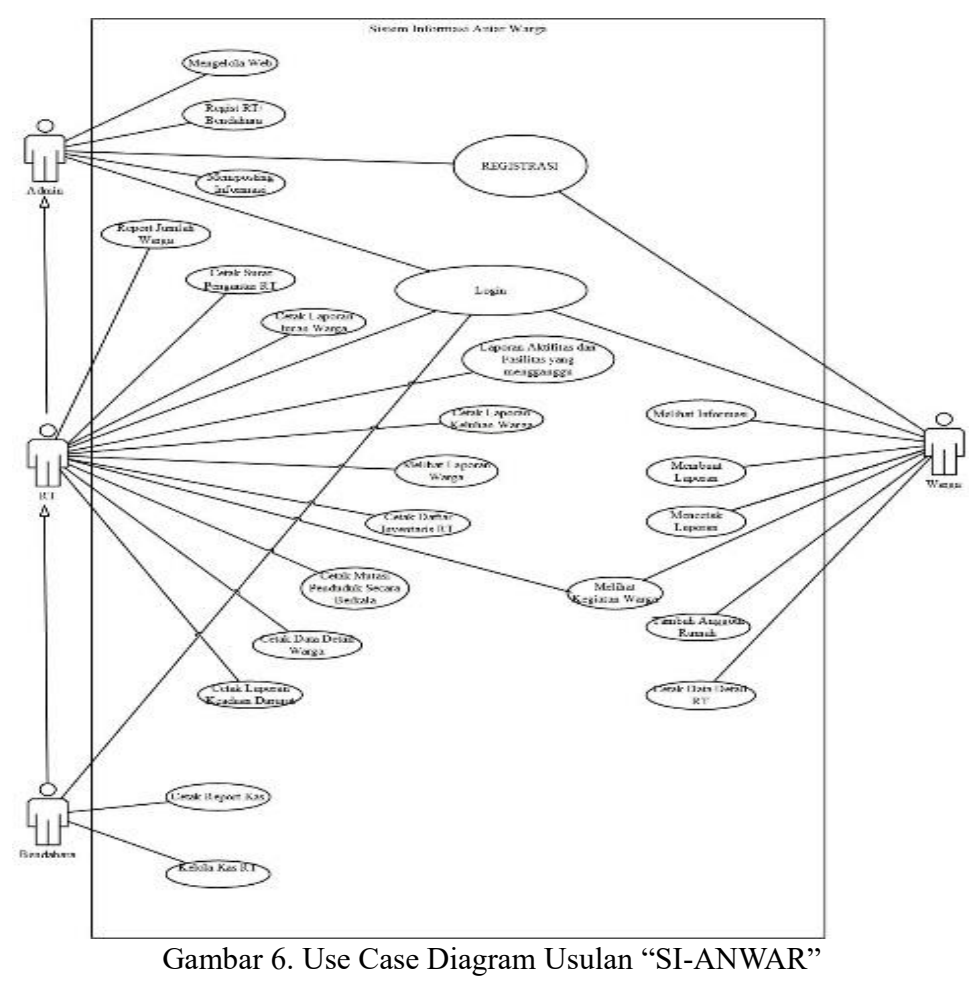




\section{Activity Diagram}

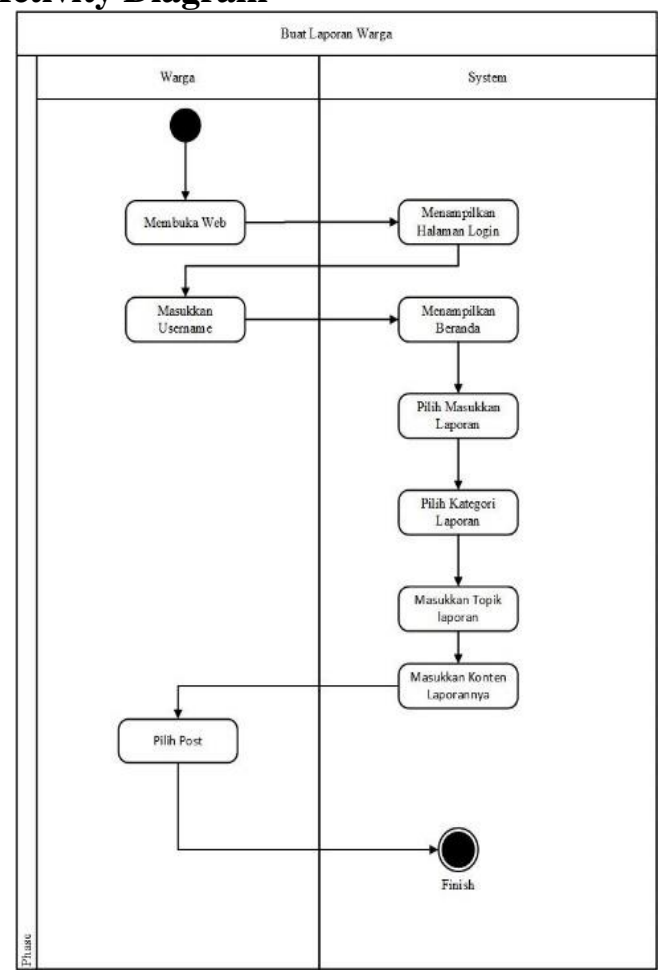

Gambar 7. Activity Diagram Buat Laporan Warga

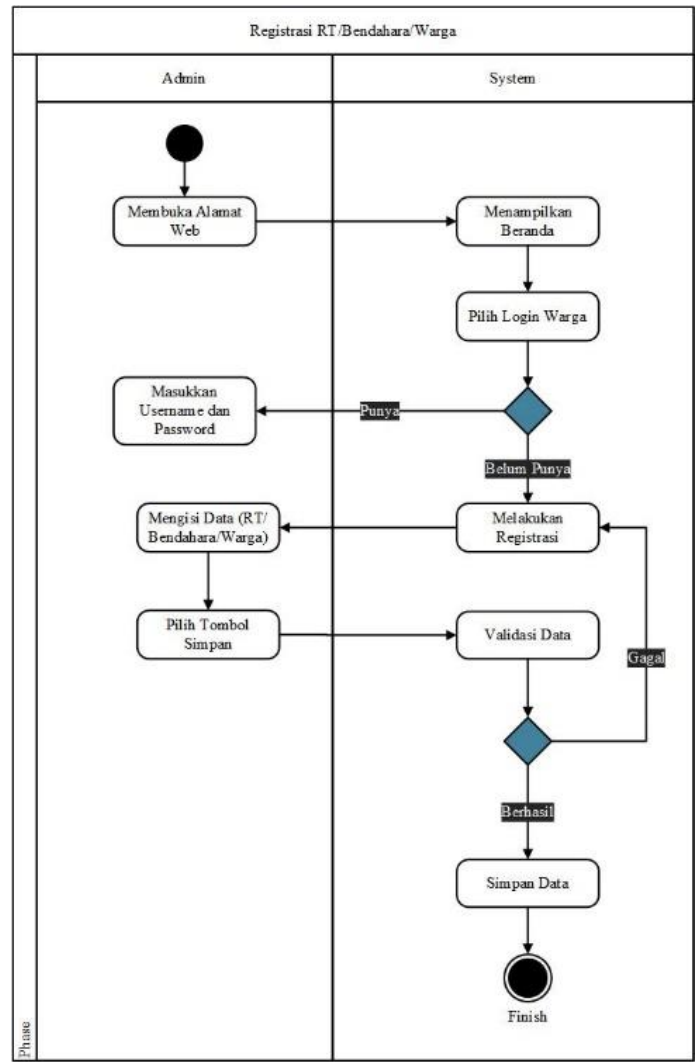

Gambar 8. Activity Diagram Registrasi RT/Warga

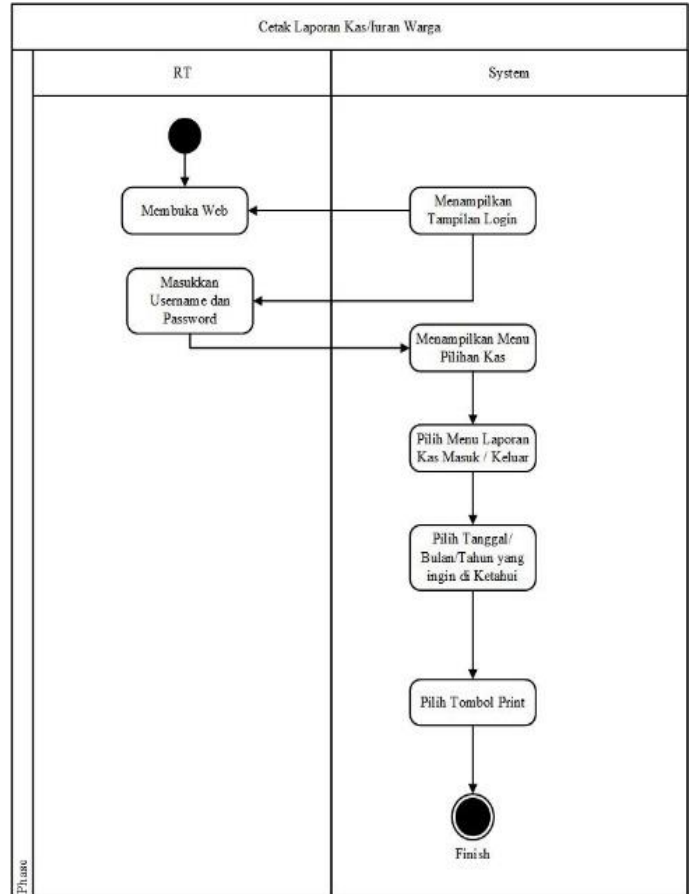

Gambar 9. Activity Diagram Cetak laporan Iuran Warga

\section{Sequence Diagram}

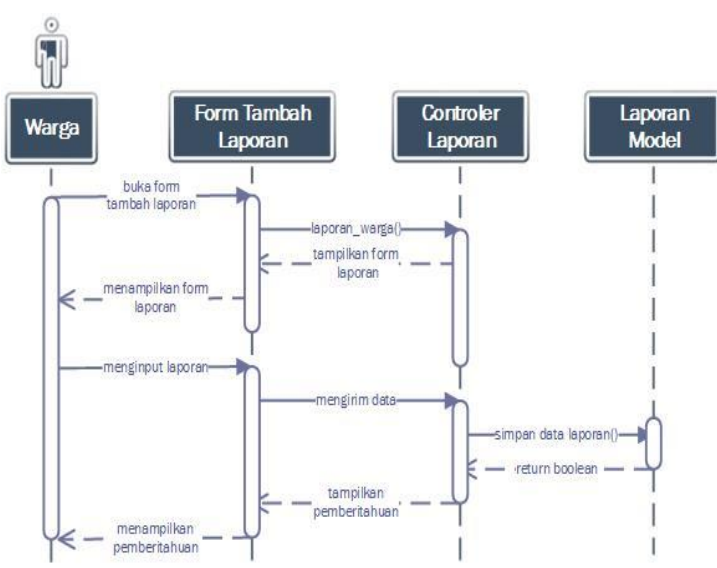

Gambar 10. Sequence Diagram Buat Laporan Warga

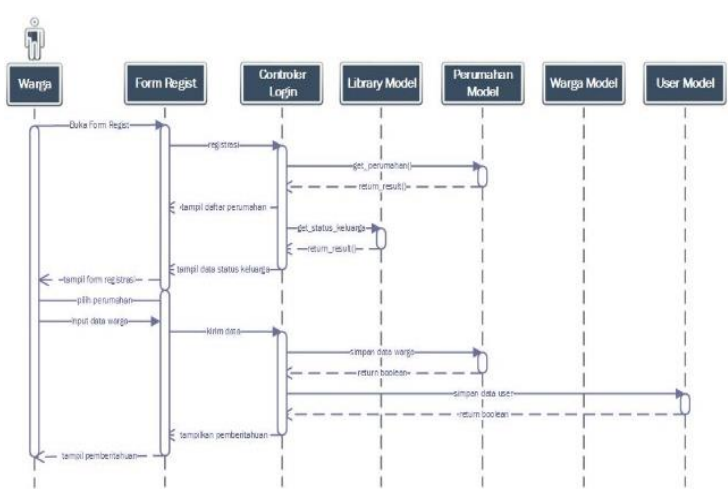

Gambar 11. Sequence Diagram Registrasi Warga/RT 


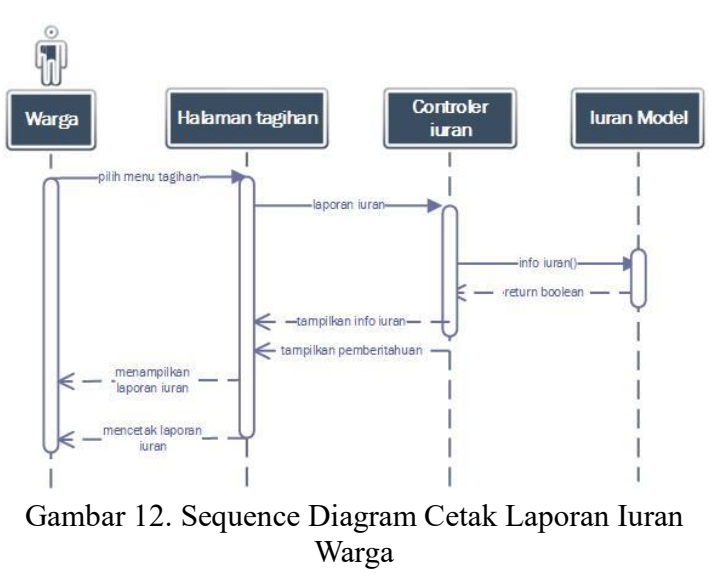

Tampilan Antar Muka

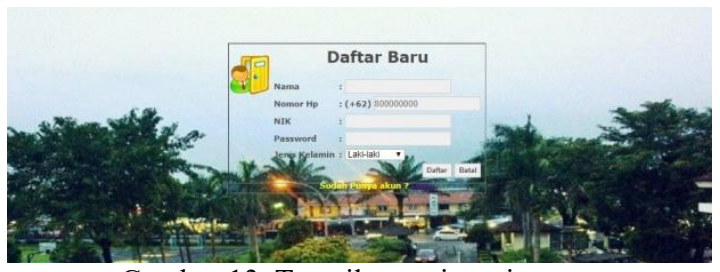

Gambar 13. Tampilan registrasi warga

Pada halaman ini user warga dapat melakukan pendaftaran sebagai user dengan mengisi form tersebut

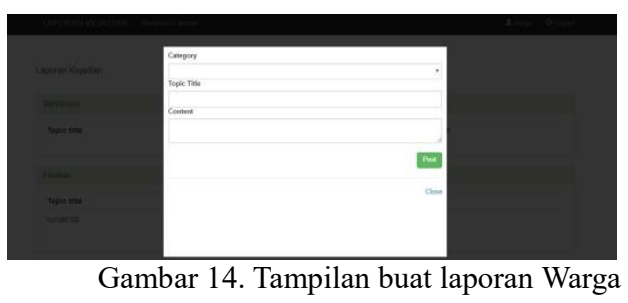

Pada halaman ini warga dapat membuat laporan terhadap kerusakan fasilitas atau keadaan darurat dengan mengisi form tersebut

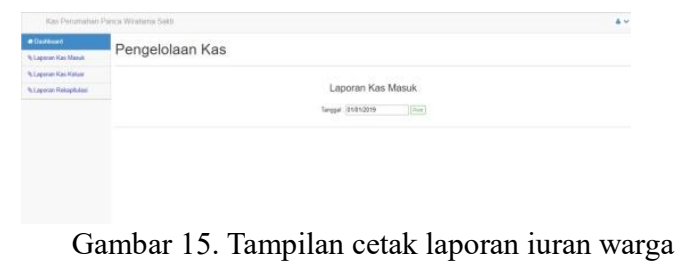

Pada halam ini user bendahara $\mathrm{rt}$ dapat mencetak laporan kas keuangan rt dengan mengklik tombol print.

\section{KESIMPULAN}

Kesimpulan yang dapat diambil dari penelitian ini yaitu sebagai berikut :
1. Perancangan aplikasi ini menyediakan informasi yang berkaitan dengan aktifitas warga dilingkungan secara online agar memudahkan warga perumahan mendapatkan informasi.

2. Perancangan aplikasi ini menyediakan layanan laporan tentang aktifitas dan fasilitas yang mengganggu kenyamanan warga di lingkungan perumahan.

3.Aplikasi ini juga bisa melaporkan kejadian darurat dengan melaporakan kejadian di menu emergency.

4. Di aplikasi ini warga bisa melihat dan mengetahui tentang tagihan iuran yang dibayarkan dan laporan iuran juga dapat di cek melalui aplikasi ini di setiap bulan nya.

\section{Daftar Pustaka}

ASNAWI, R. (2018). UPAYA SISTEM KEAMAANAN LINGKUNGAN (SISKAMLING) DALAM PENCEGAHAN PENCURIAN SEPEDA MOTOR (Studi di Wilayah Kecamatan Kalirejo Kabupaten Lampung Tengah).

Melinda, M., Borman, R. I., \& Susanto, E. R. (2017). Rancang Bangun Sistem Informasi Publik Berbasis Web (Studi Kasus : Desa Durian Kecamatan Padang Cermin Kabupaten Pesawaran). Jurnal TKSI, 11(1), 1-4.

Mukhtar. (2017). Sistem Informasi Iuran Keamanan Warga Rw.04 Kel. Tampan Kec. Payung Sekaki Berbasis Web. Intra Tech, 2(Vol 1 No 2 (2017): Jurnal Intra Tech), 10-17.

Nurnawati, E. K., \& Hibatullah, M. (2018). Sistem Pengaduan Masyarakat Untuk Melaporkan Kerusakan Fasilitas Umum Berbasis Perangkat Bergerak. XIII(November), 34-38.

Pratama, Y. A., Tania, A. S., \& Firdaus, M. T. (2018). APLIKASI SIAGA SEBAGAI SOLUSI INFORMASI ANTAR WARGA. 29-35.

Raharjo, S. M., Nurhayati, O. D., \& Martono, K. T. (2017). Sistem Informasi Pencatatan Data Warga Kelurahan Berbasis Mobile. Jurnal Teknologi Dan Sistem Komputer, 3(3), 399. https://doi.org/10.14710/jtsiskom.3.3.20 $15.399-404$ 
Rico Renaldi Polii, Rindengan, Y. D. Y., \& Karouw, S. D. S. (2017). Analisa dan Perancangan Sistem Informasi Desa Berbasis Web Model Government-toCitizen. Jurnal Teknik Informatika Unsrat, 12(1).

Roger S. Pressman, P. D. (2012). No Title (I, 1st Pub). Retrieved from http://andipublisher.com/produk0612004353-rekayasa-perangkat-lunakpendekatan-prak.html

Sri, H., \& Wijaya, R. (2016). Implementasi Web Government Sebagi Media Informasi Potensi Desa Sukaraja. 7, 63.

STMIK Pringsewu, W., \& Aprilia, S. (2017). Jurnal TAM: technology acceptance model. Jurnal TAM (Technology Acceptance Model), 4(0), 41-47. Retrieved from http://www.ojs.stmikpringsewu.ac.id/in dex.php/JurnalTam/article/view/36

Suryana, A., \& Rizki, F. (2014). Sistem Informasi Desa Ngarip Berbasis Web Kabupaten Tanggamus Lampung. Jurnal TAM (Technology Acceptance Model), 2, 53-57. 